\title{
Effect of Ca EDTA and Fe EDTA on Micro and Macro Nutrients uptake by Black gram
}

\author{
A.A. Jilani \\ Department of Chemistry, St. John's College, Agra-282002 Uttar Pradesh, India \\ E-mail: asif jilani20042003@yahoo.co.in
}

\begin{abstract}
Chelates such as EDTA and DTPA are often used to increase micronutrient solubility, but micronutrients complexed by these chelates are not readily taken up by plants. A field experiment was conducted to assess the effect of the application of EDTA on black gram crop. The aim of this study was to identify the interaction of $\mathrm{Na}, \mathrm{Ca}, \mathrm{Mg}, \mathrm{Fe}, \mathrm{Cu}$ and $\mathrm{Zn}$ when the black gram was planted on the test soil and to evaluate the effect of Ca EDTA and Fe EDTA of these metals. It was found from the study that by applying increased the organic carbon, organic matter, micronutrient i.e. Fe, Ca and $\mathrm{Zn}$ in the soil. Further it was noticed that TBS, MRP increases the $N, P$ and $K$ content in soil. From the results of this experiment, it could be concluded that individual application of Ca EDTA and Fe EDTA improved micronutrients in black gram.
\end{abstract}

Key Words: Ca EDTA, Fe EDTA, Interaction, Fe, Ca, Zn, Micronutrients

\section{Introduction}

"More than 2 billion people in the world today are estimated to be deficient in key vitamins and minerals, particularly Vitamin A, iodine, iron, and zinc. Most of these people live in low-income countries and are typically deficient in more than one micronutrient" (WHO, World Food Programme, \& UNICEF, 2007). Essential nutrients are taken up by plant roots and translocated to different plants parts. The availability of these essential elements varies from place to place may be due to the soil, environment and microbial activities. The amount of nutrient taken up by plants is a function of the amount of available nutrients in the soil. Micronutrients are essential for the normal growth of plants. Deficiencies of micronutrient drastically affect the growth, metabolism and reproductive phase in plants, animal and human beings. Wide spread deficiencies of micronutrients has been found in Indian soils (Singh, 2009).

This article is part of an overall study in which the effects of EDTA on the extractability and accumulation of micronutrients and $\mathrm{Fe}, \mathrm{Ca}$ and $\mathrm{Zn}$ by black gram crop. EDTA has been utilized in micronutrient fertilizers since 1950's (Wallace et al., 1992; Bucheli-Witschel and Egli, 2001) It was (Wallace et al. 1974) who first reported that metal-EDTA complexes could increase solubility and phytoavailability of metals in soils.

For more than 40 years, synthetic chelates have been used to supply plants with micronutrients in both soil and hydroponics. Some evidence suggests that the Fe-chelate EDTA can be absorbed by plants and translocated to shoots (Weinstein et al.; 1954, Hill-Cottingham and Liyod-Jones 1961,1965.) High organic matter (O.M.) content and cation exchange capacity (CEC) are some of the most important soil factors that determine the bioavailability of metals to plants (Liphadzi and Kirkham, 2005). Several studies showed that chemical amendments such as chelating agents increase metal availability and uptake by plants (Blaylock et al., 1997; Huang et al., 1997; Wu et al., 1999; Kirkham, 2000; Madrid et al., 2002). EDTA effectively increased the mobility of total water-soluble macronutrients $(\mathrm{Ca}, \mathrm{K}, \mathrm{Mg}$, and $\mathrm{P})$ and micronutrients $(\mathrm{Fe}, \mathrm{Mn})$ in the soil solution. Its application may increase the fertility of the soil and also in maintaining the soil $\mathrm{pH}$. Low dietary intake of $\mathrm{Ca}, \mathrm{Fe}$ and $\mathrm{Zn}$ appears to be the major reason for the widespread prevalence of $\mathrm{Ca}, \mathrm{Fe}$ and $\mathrm{Zn}$ deficiencies in human populations. In countries with a high incidence of micronutrient deficiencies, cereal-based foods represent the largest proportion of the daily diet (Cakmak 2008). In view of the above the present study was carried out to find the effect of Ca EDTA and Fe EDTA in micro and macro-nutrients of plant and seed.

\section{Material and Method}

Black gram was grown in a green house under natural light conditions in pots. The experiment was laid down in randomized Block design with twelve treatment combinations replicated thrice. The treatment consists of four levels of Ca EDTA i.e. 0,5,10 and 15 mgpot $^{-1}$ and three dose levels of Fe EDTA each i.e. 0, 5 and $10 \mathrm{mgpot}^{-1}$ as shown in table-II. About 15 seeds of black gram were sown and the pots were randomized in the greenhouse. After sprouting, black gram seedlings were thinned to 5 plants pot $^{-1}$. Chelate was injected into soil by dissolving in distilled water. Ca EDTA and Fe EDTA application in soil was carried out on 20 days after thinning and 40 days after thinning. Soil application was done in the late evening and in the morning. 
Black gram was grown for 90 days. Plants were cut $2 \mathrm{~cm}$ above the soil surface washed for no longer than 30 seconds with detergent $(0.05 \%$ Tween 80$)$, rinsed three times with deionised water and blotted dry. The plant material was dried at $65^{\circ} \mathrm{C}$ for 48 hours. For mineral nutrient analysis, samples were ground in a mill with a titanium rotar and dry ashed at $500^{\circ} \mathrm{C}$ for an hour. Thereafter $10 \mathrm{ml}$ of $6 \mathrm{M} \mathrm{HNO}_{3}$ was added to the ash residue, evaporated to dryness in a sand bath and heated to $500^{\circ} \mathrm{C}$ for 1 hour. The residue was dissolved in $6 \mathrm{M} \mathrm{HNO}_{3}$. The nutrients such as $\mathrm{Na}, \mathrm{Ca}$ and $\mathrm{Mg}$ were analyzed by atomic absorption spectrometer.. Soil Sampling: Soil was taken from surface to subsurface i.e. $0-20 \mathrm{~cm}$ and analyzed for different parameter (Table-I). The $\mathrm{pH}$ value of the soil was measured by using glass electrodes in the solution of soil in water in 1:1 ratio. ( Smith et al ,2004)]The soil is sandy loam with $\mathrm{pH}$ 7.34.The soil samples were collected $5 \mathrm{~cm}$ diameter sampler in zigzag along different transect of area until the whole area $3 \mathrm{mx} 3 \mathrm{~m}$ was covered. About $2 \mathrm{~kg}$ composite samples from 10-20 sub samples were taken in plastic bags of $4 \mathrm{~kg}$ capacities by quartering technique (EPA,1992). Composite samples of soil were rapidly air dried and then dried in oven at $105-110^{\circ} \mathrm{C}$.Later it was ground to pass 60 mesh sieve. The total concentration of $\mathrm{Zn}, \mathrm{Ca}$ and $\mathrm{Fe}$ in the soil samples were determined by using AAS and cation exchange capacity by reported method(Skinner et al,2001). The samples were analyzed for total nitrogen by Kjeldhal method (Sahrawat, 1983), K by Flame photometer (Aleksandra et al, 1975) and P by colorimeter method (Gupta et al, 1993)

All chemicals and reagent $\mathrm{s}$ used in the above experiments were of analytical grade (BDH).

TABLE I: Physico chemical properties of the study soil

\begin{tabular}{|c|c|c|c|c|c|c|c|c|c|}
\hline & & & & Total conc & ration of hea & netals $(m$ & & & \\
\hline $\mathrm{pH}$ & $\begin{array}{l}\text { Organic } \\
\text { matter\% }\end{array}$ & $\begin{array}{c}\text { Organic } \\
\text { carbon } \\
\mathrm{gKg}^{-1}\end{array}$ & $\begin{array}{l}\text { CEC } \\
\text { meq\% }\end{array}$ & $\begin{array}{c}\mathrm{CaCO}_{3} \% \\
\text { (Total) }\end{array}$ & $\begin{array}{c}\mathrm{Ca} \% \\
\text { (Available) }\end{array}$ & $\begin{array}{c}\mathrm{Fe} \\
\mathrm{mgKg}^{-1} \\
\text { (total) }\end{array}$ & $\begin{array}{l}\mathrm{Fe} \mathrm{mgKg}^{-1} \\
\text { (Available) }\end{array}$ & $\begin{array}{c}\mathrm{Zn} \\
\mathrm{mgKg}^{-1} \\
\text { (total) }\end{array}$ & $\begin{array}{c}\mathrm{Zn} \\
\mathrm{mgKg}^{-1} \\
\text { (Available } \\
\text { ) }\end{array}$ \\
\hline 7.28 & 8.5 & 4.8 & 12.9 & 13.3 & 1.07 & 22190 & 33.3 & 58.8 & 1.8 \\
\hline
\end{tabular}

Table-II Treatment Description

\begin{tabular}{|c|c|c|}
\hline Treatment & Doses & Symbol \\
\hline Ca EDTA & 0 & CaE0 \\
\cline { 2 - 3 } & 5 & CaE5 \\
\cline { 2 - 3 } & 10 & CaE10 \\
\cline { 2 - 3 } & 15 & CaE15 \\
\hline Fe EDTA & 0 & FeE0 \\
\cline { 2 - 3 } & 5 & FeE5 \\
\cline { 2 - 3 } & 10 & FeE10 \\
\hline
\end{tabular}

III. Statistical Analysis

The observed quantitative data were tabulated to statistical analysis with the help of ANNOVA. The F-test was used to determine whether any real difference between the treatments exist or there were only error of sampling. The composition of testing the significance was made at 5\% level.

\section{The interaction of $\mathrm{N}, \mathrm{P}, \mathrm{K}, \mathrm{Na}$ and $\mathrm{Mg}$ -}

\section{Result and Discussion}

It is revealed from the data pertaining to $\mathrm{N}$ content given in table III and IV clearly indicated that the $\mathrm{N}$ content in black gram plant and seed increased with the rise in Ca EDTA and Fe EDTA. The maximum $\mathrm{N}$ concentration in plant was found at CaE15FeE0 level, i.e.1.48 mg pot ${ }^{-1}$ and for seed was observed at CaE10FeE0 i.e. $1.41 \mathrm{mg} \mathrm{pot}^{-1}$.It is revealed that fertilization of Ca EDTA and Fe EDTA found significant superior over control. The increased $\mathrm{N}$ content with chelating agent application may be ascribed to increased root system and higher absorbing capacity. Phosphorus is an essential element in plants, and deficiency can significantly limit plant growth. The highest phosphorus concentration in plant and seed was obtained at $\mathrm{CaE} 15 \mathrm{Fe} 10$ level i.e. 9.57 mg-1 and $4.14 \mathrm{mg}^{-1}$ respectively. It is further revealed that application also found significant in both plant and seed.(Table III and IV) It is obvious that due to interactive effect of Ca EDTA and Fe EDTA.

Table-III Interaction Effect of chelates in black gram plant

\begin{tabular}{|c|c|c|c|c|}
\hline Element & Ca EDTA ppm pot & \multicolumn{2}{|c|}{ Fe EDTA ppm pot $^{-1}$} \\
\hline & Treatment & FeE0 & FeE5 & FeE10 \\
\hline $\mathbf{N}$ & MeanSEm \pm 0.10 & 1.26 & 1.28 & 1.31 \\
\hline $\mathbf{P}$ & MeanSEm \pm 0.04 & 8.08 & 8.27 & 8.59 \\
\hline $\mathbf{K}$ & MeanSEm \pm 1.28 & 46.83 & 47.83 & 50.42 \\
\hline $\mathbf{N a}$ & MeanSEm \pm 0.99 & 32.25 & 35.75 & 38.5 \\
\hline $\mathbf{C a}$ & MeanSEm \pm 0.46 & 6.83 & 6.17 & 7.83 \\
\hline $\mathbf{M g}$ & MeanSEm \pm 0.33 & 1.08 & 0.92 & 1.25 \\
\hline $\mathbf{F e}$ & MeanSEm \pm 1.61 & 20.74 & 20.75 & 20.76 \\
\hline $\mathbf{Z n}$ & MeanSEm \pm 0.23 & 2.02 & 2.05 & 2.35 \\
\hline
\end{tabular}


Effect of Ca EDTA and Fe EDTA on Micro and Macro Nutrients uptake by Black gram

Table-IV Interaction Effect of chelates in black gram seed

\begin{tabular}{|c|c|c|c|c|}
\hline Element & Ca EDTA ppm pot & \multicolumn{2}{|c|}{ Fe EDTA ppm pot $^{-1}$} \\
\hline $\mathbf{N}$ & Treatment & FeE0 & FeE5 & FeE10 \\
\hline $\mathbf{P}$ & MeanSEm \pm 0.18 & 1.26 & 1.27 & 1.28 \\
\hline $\mathbf{K}$ & MeanSEm \pm 0.45 & 2.96 & 3.17 & 3.40 \\
\hline $\mathbf{N a}$ & MeanSEm \pm 1.68 & 27.33 & 30.67 & 32.34 \\
\hline $\mathbf{C a}$ & MeanSEm \pm 0.48 & 9.08 & 10.67 & 11.50 \\
\hline $\mathbf{M g}$ & MeanSEm \pm 0.40 & 2.17 & 1.58 & 2.08 \\
\hline $\mathbf{F e}$ & MeanSEm \pm 0.35 & 1.42 & 1.25 & 1.83 \\
\hline $\mathbf{Z n}$ & MeanSEm \pm 0.02 & 16.24 & 17.60 & 18.35 \\
\hline
\end{tabular}

It is further noted that Potassium content increased significantly to a greater extent at higher concentration of Ca EDTA and Fe EDTA while it tremendously reduced with decreasing levels of chelating agents. The maximum $\mathrm{K}$ concentration in plant was observed in both the cases of plant and seed. The maximum $\mathrm{K}$ concentration was observed at $\mathrm{CaE} 10 \mathrm{FeE} 10$ i.e. $62.33 \mathrm{ppm}$ while minimum was recorded at control level i.e. $33.67 \mathrm{ppm}$. The potassium concentration in the seed also follow the same trend.

The CaE0FeE0 did not increase the sodium concentration in comparison to the other levels. The minimum values of $\mathrm{Na}$ content in the plant and seed was recorded in control. The increase in Na content because of higher concentration of $\mathrm{Na}$ in soil solution. The maximum value of sodium concentration of plant and seed was found at CaE10FeE10 level at 51.33 and $15.67 \mathrm{ppm}$ respectively. From the data it is further revealed that interaction effect of compounds is found to be significant in both plant and seed. It is obvious from the data pertaining to uptake in plant and seed that higher concentration of Ca EDTA and Fe EDTA did not significantly increase the Magnesium content in appreciable manner in both plant and seeds. The highest Magnesium uptake in plant got increased at CaE10FeE10 level i.e.2.00 ppm. Similar trend was also observed in seed where interaction increased $\mathrm{Mg}$ uptake maximum at $2.67 \mathrm{ppm}$. It is found that these results were significant at $5 \%$ level of significance.

\section{The interaction of $\mathrm{Ca}$, Fe and Zinc-}

From the examined data, it was found that there was significant increased with increase in chemical ameliorants which slightly increased the Fe uptake over control. It was further revealed from the data that higher concentration of EDTA increased the Fe content in plant and seeds whereas better results were obtained at medium concentration (table-III and IV). These results are in favours of the results given by Smith et al (2004) .The treatment does not show any significant difference $(p<0.05)$. Luo et al $(2006)$ also reported that EDTA is an effective chelate for mobilizing the metal from the contaminated soils and for enhancing the uptake of metal by the hyperaccumulater like thlaspi and Brassica junceae. From the results it was found that the zinc content increased in appreciable proportion in all treatments positively correlated with increasing concentrations of $\mathrm{Zn}$ in the sample $(\mathrm{p}<0.05)$. It is evident from the data that due to interaction effect of EDTA and Fe EDTA, zinc concentration went high (table- III and IV). It is further revealed that these results are found to be more encouraging as compared from the other treatments. These results are in consonance with the findings of Collins et al (2002). Gangloff et al (2006) also suggested that ZnSO4 and Zn-EDTA were always the most effective material in supplying the plants need.

\section{Statistical Analysis-}

The observed quantitative data tabulated to statistical analysis with the help of variance (ANOVA) technique. The F-test was used to determine whether any real difference between the treatments existed or there were only error of sampling, the composition for treating the significance was made at $5 \%$ level. The results were analyzed and found significant at $5 \%$ level (Table-V).

Table-V Result of ANNOVA for nutrients concentration in black gram crop

\begin{tabular}{|c|c|c|c|c|c|c|c|c|}
\hline \multirow{2}{*}{$\begin{array}{c}\text { Sources/ } \\
\text { Variables }\end{array}$} & \multirow[t]{2}{*}{ df } & \multicolumn{7}{|c|}{ Micro and Macro nutrients in plants } \\
\hline & & $\mathbf{N}$ & $\mathbf{P}$ & $\mathbf{K}$ & $\mathrm{Na}$ & Ca & $\mathbf{F e}$ & Zn \\
\hline factor-1 & 3 & $7.8^{* * *}$ & $2023.93 * *$ & $270.38 * *$ & $386.37 * *$ & $40.49 * *$ & $58.35 * *$ & $19.67 * *$ \\
\hline factor-2 & 2 & $0.26^{*}$ & $177.08 * *$ & $8.37 * *$ & $40.16^{* *}$ & $13.32 * *$ & $0.05^{*}$ & $2.69 * *$ \\
\hline Interaction & 6 & $0.1^{*}$ & $48.33^{*}$ & $4.01 * *$ & $10.15 * *$ & $7.71 * *$ & $2.99 * *$ & $13.54 * *$ \\
\hline & & \multicolumn{6}{|c|}{ Micro and Macro nutrients in seed } & \\
\hline factor-1 & 3 & $53766.63 * *$ & $9.76^{* *}$ & $60.63^{* *}$ & $251.92 * *$ & $5.7 * *$ & $57819.49 * *$ & $2.31 *$ \\
\hline factor-2 & 2 & $1906.92 * *$ & $0.98 * *$ & $9.24 * *$ & $25.95 * *$ & $2.52 *$ & $7361.1 * *$ & $81.35 * *$ \\
\hline Interaction & 6 & $1044.07 * *$ & $0.49 *$ & $1.44^{*}$ & $4.74 * *$ & $3.06 * *$ & $3502.19 * *$ & $309.98 * *$ \\
\hline
\end{tabular}

df- degree of freedom

$* *$ Significant $\mathrm{p}<0.05$

*non significant 


\section{References}

[1]. Aleksandra Sobkowska, Maria Basińska, Flame photometry determination of Na, K, Li, and Ca traces in Cr-Ni steel, Microchimica Acta, 64,1975,227-234

[2]. Gupta, A.P., Neue, H.U. and Singh, V.P. Phosphorus determination in rice plants containing variable manganese content by the phospho-molybdo-vanadate (yellow) and phosphomolybdate (blue) colorimetric methods, Communications in Soil Science and plant Analysis (11-12), 1993, 1309-1318

[3]. Blaylock, M.J., Dushenkov, D.E., Zakharova, S., Gussman, O., Kapulnik, C.,Ensley, Y. Raskin, B.D., Enhanced accumulation of $\mathrm{Pb}$ in Indian mustard by soil-applied chelating agents. Environmental Science and Technology, 64, 1997, 489-496

[4]. Bucheli-Witschel, M., Egli, T., Environmental fate and microbial degradation of aminopolycarboxylic acids. FEMS Microbiol. Rev.2001, 25, 69-106.

[5]. Cakmak, I,Enrichment of cereal grains with zinc: Agronomic or genetic biofortification Plant and Soil 302, 2008, 1-17

[6]. Collins, R N., Merrington, G., McLaughlin, M J., and Knudsen, C., Uptake of intact zinc Ethylenediamine tetraacetic acid from soil is dependent on plant species and complex concentration. Environ. Toxicol. Chem. 21, 2002, 1940-1945

[7]. EPA/600/R-92/128, Preparation of Soil Sampling Protocols: Sampling Techniques and Strategies, July 1992

[8]. Gangloff, W.J.; Westfall, D.G.; Peterson, G.A.; and Mortvedt, J.J. Mobility of Organic and Inorganic Zinc Fertilizers in Soils. Comm. Soil Sci. Plant Analysis.37, 2006, 199-209

[9]. Hill-Cottingham, DG., Llyod-Jones, CP. Absorption and breakdown of iron-ethylenediamine tetraacetic acid by tomato plants. Nature, 1961, 189-312

[10]. Hill-Cottingham, DG., Llyod-Jones, CP, The behaviour of iron chelating agents with plants. J Exp Bot 16, $1965,233-242$.

[11]. Huang, J.W., Chen, J., Berti,W.R., Cunningham, D.S, Phyto-remediation of lead contaminated soils: role of synthetic chelates in lead phytoextraction., Environmental Science and Technology 31,1997, 800-805

[12]. IITA, Selected methods for soil and plant analysis Manual series, 1982, No 7, IITA Ibadan [13]. Kirkham, M.B,EDTA-facilitated phytoremediation of soil with heavy metals from sewage sludge. International Journal of Phytoremediation 2, 2000, 159-172.

[13]. Liphadzi, M.S., Kirkham, M.B. Phytoremediation of soil contaminated with heavy metals a technology for rehabilitation of the environment. South African Journal of Botany71, 2005, 24-37

[14]. Luo,C., Shen,Z., L. Lou, Li,X., EDDS and EDTA-enhanced phytoextraction of metals from artificially contaminated soil and residual effects of chelant compounds, Environ. Pollut. 144, :2006, 862

[15]. Madrid, F., Liphadzi, M.S., Kirkham, M.B. Heavy metal displacement in chelate-irrigated soil during phytoremediation. Journal of Hydrology 272, 2002, 107-119.

[16]. Skinner,M.F.,Zabowski d.,Harrison R.,Lowe A., and Xue D.Measuring the cation exchange capacity of forest soils, Commun. Soil Sci. Plant Anal. 32(11\&12), 2001, 1751-1764

[17]. Sahrawat,.K.L., (1983),Correlations between indexes of soil nitrogen availability and nitrogen percent in plant, nitrogen uptake, and dry-matter yield of rice grown in the greenhouse, Plant and Soil, 74(2), 1983, pp 223-228

[18]. Singh,M.V., Micronutrient nutrional problems in Soils of India and Improvement for human and animal Health. Indian J.fert.,5(4), 2009, 11-16

[19]. Smith Brandon R.,Fisher Paul., and Argo William R.,Water soluble Fertilizer Concentration and pH of a peat based substrate growth,nutrition uptake and Chlorosis of container grown seed geranius" J of plant Nutrition, 27(3), 2004.497-524

[20]. Wallace, A., Muller, R.J., Cha, J.W., Alexander, G.V., Soil pH excess lime and chelating agent on micronutrients in soybeans and bush beans. Agron. J. 66, 1974, 698-700.

[21]. Wallace, A., Wallace, GA., Some of the problems concerning iron nutrition of plants after four decades of synthetic chelating agents. J Plant Nutrition 15, 1992, 1487-1508.

[22]. Weinstein, LH., Robbins, WR., Perkins, HF., Chelating agents and plant nutrition. Science 120, 1954, 41-43.

[23]. WHO, World Food Programme, \& UNICEF. Preventing and controlling micronutrient deficiencies in populations affected by an emergency. (Geneva, Switzerland: WHO. Retrieved on December 20, 2007)

[24]. Wu, J., Hsu, F.C., Cunningham, S.D., Chelate-assisted Pb phytoextraction: $\mathrm{Pb}$ availability, uptake, and translocation constraints. Environmental Science and Technology 33, 1999, 1898-1904 